\title{
Randomised controlled trial of oxytocin alone versus oxytocin and ergometrine in active management of third stage of labour
}

\author{
Susan J McDonald, Walter J Prendiville, Eve Blair
}

\begin{abstract}
Objective-To compare intramuscular oxytocin alone and intramuscular oxytocin with ergometrine (Syntometrine) for their effect in reducing the risk of postpartum haemorrhage when both are used as part of the active management of the third stage of labour.

Design-Double blind, randomised controlled trial.

Setting-Two metropolitan teaching hospitals in Perth, Western Australia.

Subjects-All women who expected a vaginal birth during the period of the trial. Informed consent was obtained.

Main outcome measures-Postpartum haemorrhage, nausea, vomiting, and increased blood pressure.

Results-3497 women were randomly allocated to receive oxytocin-ergometrine $(n=1730)$ or oxytocin $(n=1753)$. Rates of postpartum haemorrhage $(\geqslant 500 \mathrm{ml}$ or $\geqslant 1000 \mathrm{ml}$ ) were similar in both arms (odds ratio $0.90(0.82) ; 95 \%$ confidence interval 0.75 to $1.07(0.59$ to 1.14$)$ at $500 \mathrm{ml}(1000 \mathrm{ml})$ threshold $)$. The use of oxytocin-ergometrine was associated with nausea, vomiting, and increased blood pressure.

Conclusions-There are few advantages but several disadvantages for the routine use of oxytoxinergometrine when prophylactic active management of the third stage of labour is practised. Further investigation of dose-response for oxytocin may be warranted.
\end{abstract}

\section{Introduction}

The best estimates of global mortality for mothers in childbirth are about 500000 a year. ${ }^{2}$ Most of these result from complications of the third stage of labour and in particular from postpartum haemorrhage. Nearly all maternal deaths $(99 \%)$ occur in the developing world, ${ }^{2}$ where other factors may contribute to death in the presence of severe postpartum haemorrhage. Many more women survive and suffer serious illness as a result, not only from the effects of acute anaemia but also from the interventions which a severe haemorrhage may necessitate (general anaesthesia, manual removal of the placenta, blood transfusion).

Reducing the likelihood of postpartum haemorrhage by routine management of the third stage of labour could play an important part in reducing maternal morbidity and mortality. ${ }^{3}$ The results of two large randomised controlled trials suggest that active management of the third stage as a routine preventive measure (administration of an oxytocic, cord clamping, and cord traction) is associated with a twofold to threefold reduction in the risk of postpartum haemorrhage. ${ }^{67}$ Although active management is routine practice in the United Kingdom ${ }^{5}$ and some other Western countries, evaluation of the individual components that make up active management is incomplete. ${ }^{8}$

The routine prophylactic administration of an oxytocic agent is an integral part of the active management of labour and seems to reduce the risk of postpartum haemorrhage by about $40 \%{ }^{4}$ The two most widely used oxytocic agents are oxytocin and Syntometrine (ergometrine $0.5 \mathrm{mg}$ in combination with oxytocin $5 \mathrm{IU})$. In a meta-analytical overview in 1988 Elbourne et al attempted to determine which prophylactic oxytocic agent was associated with the least risk of postpartum haemorrhage and stated that "a mixture of ergometrine and oxytocin (Syntometrine) appears to be the safest and most effective prophylactic of the alternatives compared, but the quality of evidence is not satisfactory." They concluded that there was scope for a randomised comparison of oxytocin-ergometrine and oxytocin. A World Health Organisation technical working group convened in Geneva in 1989 to discuss the prevention and management of postpartum haemorrhage came to a similar conclusion, adding further impetus for the completion of such a study. ${ }^{3}$

Our objective was to determine which of the two most commonly used prophylactic oxytocic agents (oxytocin $10 \mathrm{IU}$ and oxytocin-ergometrine) was associated with the lowest risk of postpartum haemorrhage when used intramuscularly as part of the routine active management of the third stage of labour. We also wanted to determine an unbiased and more precise estimate of their relative effects on blood pressure and vomiting.

\section{Subjects and methods}

POWER CALCULATIONS

Active management is routine policy at the King Edward Memorial Hospital for Women in Perth, Western Australia. Oxytocin is preferred in women with hypertension or cardiac disease; otherwise the choice of oxytocic is left to the midwife or obstetrician. In practice two thirds use oxytocin-ergometrine. In the Bristol third stage trial, when oxytocin-ergometrine was used as the routine oxytocic the incidence of postpartum haemorrhage was about $5 \% .{ }^{4}$ We estimated that if oxytocin-ergometrine reduced the risk of postpartum haemorrhage to $5 \%$ from a "best guess estimate" of $7.5 \%$ for oxytocin this difference would be sufficient to influence the choice of oxytocic in clinical practice. A sample size of at least 3100 would be required to have an $80 \%$ chance of detecting such a difference at a significance of $p \leqslant 0.05$.

\section{RECRUITMENT}

All women who expected a vaginal birth at the hospital during the study period (19 February 1990 to 20 October 1991) were invited to participate. From 3 February 1991 until 20 October 1991 recruitment 
was extended to include similar women from another metropolitan hospital (Osborne Park Hospital). Table I lists exclusion criteria.

TABLE I-Details of subjects in trial of oxytocin (o) $v$ oxytocinergometrine (o-e) in third stage of labour

\begin{tabular}{lc}
\hline Detail & $\begin{array}{c}\text { No }(\%) \\
\text { women }\end{array}$ \\
\hline $\begin{array}{l}\text { Women delivered within trial } \\
\text { Women delivered but not in trial } \\
\quad \text { Reasons for non-participation }\end{array}$ & 3497 \\
Planned caesarean section & 4816 \\
General anaesthetic for operative delivery & $1311(27 \cdot 2)$ \\
other than caesarean section & \\
Antepartum hypertension & $22(0 \cdot 5)$ \\
Maternal refusal & $495(10 \cdot 3)$ \\
Other (maternal distress, advanced stage in & $1112(23 \cdot 1)$ \\
labour, language barrier, fetal abnormality & \\
or death in utero, medical disease) & \\
Reasons for non-compliance with allocation $(0 ; 0-e) *$ & $1876(38 \cdot 9)$ \\
Emergency caesarean section & \\
Blood pressure $>150 / 100$ mm Hg in labour & $42 ; 45$ \\
Administrative error & $15 ; 23$ \\
Maternal request & $5 ; 7$ \\
Clinical request & $1 ; 3$ \\
Reason unclear & $6 ; 7$ \\
\end{tabular}

* $n=176$. Fourteen ampoules of drug discarded before number was recorded.

CONSENT

Information sheets explaining the aims of the trial were distributed to potential participants either in the antenatal clinic or, in the case of privately insured women, on admission to the delivery ward as this was most often the first contact point with hospital midwifery staff. Written informed consent was obtained, and a contact number was given to all participants on which they could seek further information about the trial or ask any questions.

\section{RANDOMISATION}

On admission to the delivery room the woman was reminded about the trial. If she did not withdraw at this stage she was deemed to have entered the trial. When the attending midwife considered a vaginal birth was imminent the next available numbered trial ampoule was administered by intramuscular injection at the time of the birth of the anterior shoulder of the baby. The ampoules were numbered by Sandoz by using simple randomisation. There was no blocking or prognostic stratification.

The attendant was blind to the random allocation. In the event of a massive haemorrhage, or if the clinician needed to know which oxytocic agent had been given before ordering subsequent oxytocic treatment, the chief pharmacist at King Edward Memorial Hospital would on request break the code.

\section{ASSESSMENT OF BLOOD LOSS}

Blood loss was estimated clinically by the attendant midwife or obstetrician. A sample of venous blood $(5 \mathrm{ml})$ was obtained two days after the birth for haemoglobin measurement from each woman in the trial as an extra and objective index of blood loss. In addition, data were collected on a number of other maternal and neonatal outcomes.

\section{DATA COLLECTION}

In the labour ward the relevant trial information was recorded on a data sheet by the midwife supervising the delivery. These sheets were collected and checked by the midwife researcher. Additional information for comparability of the trial population was extracted either through the hospital's computerised system for the collection of obstetric data or by manual extraction from individual medical record folders. A pilot study was carried out in January 1990. No adjustments were made to the protocol before the start of the main trial.
STATISTICAL METHODS

The study was analysed on an intention to treat basis. All women allocated to receive a drug were included in that group, excluding only the 14 women for whom drug allocation was not recorded. All calculations are therefore based on the numbers of women allocated to the two groups, except when there were substantial missing values. In the few such cases the base numbers are shown. Outcomes were expressed as dichotomous variables according to clinically meaningful criteria and as the estimated odds for an adverse outcome if allocated oxytocin-ergometrine relative to those allocated oxytocin. The means of continuous variables were also compared by using Student's $t$ test. Similar analyses based on the oxytocic agent actually received and stratified by perceived risk of problems with the third stage were performed when appropriate.

INTERIM ANALYSIS

An independent data monitoring committee, comprising an obstetrician, a midwife, and an epidemiologist, met in October 1990 and reviewed the anonymous data collected from 1376 women who had been recruited to the study. The committee recommended that the study continue until complete recruitment of the sample size.

\section{Results}

The total number of women giving birth in the two participating hospitals from 19 February 1990 to 20 October 1991 was 8313 . Of these, 3497 were recruited. A total of 176 women who were allocated a trial ampoule did not receive their allocated oxytocic agent. Reasons for this and for non-participation in the trial are listed in table I. The randomly allocated groups were comparable in terms of sociodemographic characteristics, obstetric history, antenatal haemoglobin concentration, variables of labour (table II), and the actual management of the third stage (table III).

Postpartum haemorrhage was initially defined as $\geqslant 500 \mathrm{ml}$, in keeping with the previous study. ${ }^{4}$ By using this definition the rate in women allocated oxytocin

TABLE II-Details of two groups of women and their labours and deliveries in trial of oxytocin-ergometrine versus oxytocin in third stage of labour. Figures are numbers (percentages) unless otherwise stated

\begin{tabular}{|c|c|c|}
\hline Details of mother and delivery & $\begin{array}{l}\text { Oxytocin- } \\
\text { ergometrine } \\
(\mathrm{n}=1713)\end{array}$ & $\begin{array}{c}\text { Oxytocin } \\
(\mathrm{n}=1727)\end{array}$ \\
\hline \multicolumn{3}{|l|}{ Sociodemographic variables: } \\
\hline Mean (SD) maternal age (years) ${ }^{\star}$ & $26 \cdot 8(5 \cdot 8)$ & $26 \cdot 8(5 \cdot 8)$ \\
\hline Married women & $1363(79 \cdot 6)$ & $1334(77 \cdot 2)$ \\
\hline Primiparous women & $804(47 \cdot 0)$ & $854(49 \cdot 4)$ \\
\hline \multicolumn{3}{|c|}{ Obstetric history—previous third stage problems: } \\
\hline Postpartum haemorrhage & $3(0 \cdot 2)$ & $2(0 \cdot 1)$ \\
\hline Manual removal of placenta & $158(9 \cdot 2)$ & $180(10 \cdot 5)$ \\
\hline $\begin{array}{l}\text { Mean (SD) lowest antenatal haemoglobin } \\
\text { concentration } \ddagger\end{array}$ & $11.4(1 \cdot 1)$ & $11 \cdot 4(1 \cdot 1)$ \\
\hline \multicolumn{3}{|l|}{ Labour: } \\
\hline Spontaneous onset & $1166(68 \cdot 1)$ & $1147(66 \cdot 4)$ \\
\hline Oxytocic induction or augmentation & $737(43 \cdot 0)$ & $785(45.5)$ \\
\hline Epidural in 1st or 2nd stage & $619(36 \cdot 1)$ & $669(38 \cdot 7)$ \\
\hline Mean (SD) length I st stage (hours) & $6 \cdot 23(4 \cdot 4)$ & $6 \cdot 25(4 \cdot 5)$ \\
\hline Mean (SD) length 2nd stage (min) $\int$ & $53.8(57 \cdot 3)$ & $54.4(59.9)$ \\
\hline Intact perineum & $676(39 \cdot 5)$ & $674(39 \cdot 0)$ \\
\hline \multicolumn{3}{|l|}{ Type of delivery: } \\
\hline Spontaneous cephalic & $1328(77 \cdot 5)$ & $1322(76 \cdot 5)$ \\
\hline Forceps or ventouse & $325(19 \cdot 0)$ & $336(19 \cdot 6)$ \\
\hline Caesarean section & $47(2 \cdot 7)$ & $45(2 \cdot 6)$ \\
\hline Vaginal breech & $9(0.5)$ & $22(1 \cdot 3)$ \\
\hline \multicolumn{3}{|l|}{ Risk categories for women\|: } \\
\hline Low risk & 664 & 658 \\
\hline Not low risk & 1048 & 1067 \\
\hline
\end{tabular}

*Oxytocin-ergometrine, $n=1708 ;$ oxytocin, $n=1722$. †Oxytocin-ergometrine, $n=1553$; oxytocin, $n=1560$. foxytocin-ergometrine, $n=1553$; oxytocin, $n=1560$ fOxytocin-ergometrine, $n=1355$; oxytocin, $n=1380$. Oxytocin-ergometrine, $n=1730$; oxytocin, $n=1753$.

|Low risk defined as presence of all of following: singleton pregnancy; no previous third stage problems; parity $<5$; spontaneous onset of labour; no oxytocic augmentation of labour; labour lasting $<12$ hours; spontaneous vaginal delivery. 
$(18.06 \%)$ was not significantly different from that in women allocated oxytocin-ergometrine $(16.55 \%)$. In view of unexpectedly high rates (see discussion) severe postpartum haemorrhage was defined as $\geqslant 1000 \mathrm{ml}$ loss. Again, allocation to oxytocin-ergometrine was associated with a lower rate $(3.93 \%)$ of haemorrhage than allocation to oxytocin $(4 \cdot 73 \%)$ (table IV); but the difference was not significant. If we redefined moderate postpartum haemorrhage as $>500 \mathrm{ml}$ and severe as $>1000 \mathrm{ml}$ a sizeable proportion of the women included by the initial criteria for postpartum haemorrhage fell precisely on the cut off points at $500 \mathrm{ml}$ $(16.3 \%)$ and $1000 \mathrm{ml}(22 \cdot 5 \%)$. These happened to be unevenly distributed between the two arms of the

TABLE III-Details of deliveries in trial of oxytocin-ergometrine versus oxytocin in third stage of labour. Figures are numbers (percentages)

\begin{tabular}{lcc}
\hline & $\begin{array}{c}\text { Oxytocin- } \\
\text { ergometrine } \\
(\mathrm{n}=1713)^{\star}\end{array}$ & $\begin{array}{c}\text { Oxytocin } \\
(\mathrm{n}=1727) \dagger\end{array}$ \\
Detail & & \\
\hline Cord clamping: & $182(10 \cdot 6)$ & $196(11 \cdot 3)$ \\
After delivery of baby's head & $1242(72 \cdot 5)$ & $1286(74 \cdot 5)$ \\
Within 30 s after delivery & $188(11 \cdot 0)$ & $163(9 \cdot 4)$ \\
Delayed > 1 min & $111(6 \cdot 5)$ & $97(5 \cdot 6)$ \\
When cord pulsation ceased & $5(0 \cdot 3)$ & $11(0 \cdot 6)$ \\
Not recorded & $7(0 \cdot 4)$ & $5(0 \cdot 3)$ \\
Cord traction: & $28(1 \cdot 6)$ & $41(2 \cdot 4)$ \\
No cord traction & $93(5 \cdot 4)$ & $110(6 \cdot 4)$ \\
Within 30 s after delivery & $1560(91 \cdot 1)$ & $1548(89 \cdot 6)$ \\
Before signs of separation & $42(2 \cdot 5)$ & $49(2 \cdot 8)$ \\
After signs of separation & $195(11 \cdot 4)$ & $180(10 \cdot 4)$ \\
Not recorded & $313(18 \cdot 3)$ & $342(19 \cdot 8)$ \\
Who managed third stage: & $643(37 \cdot 5)$ & $669(38 \cdot 7)$ \\
Consultant & $368(21 \cdot 5)$ & $346(20 \cdot 0)$ \\
Other medical officer & $209(12 \cdot 2)$ & $210(12 \cdot 2)$ \\
Registered midwife & $2(0 \cdot 1)$ & $6(0 \cdot 3)$ \\
Student midwife & & \\
Medical student & & \\
Not recorded & &
\end{tabular}

ata not available for 17 women and 16 babies.

tData not available for 26 women and 25 babies.

TABLE IV-Prevalences and odds ratios for postpartum haemorrhage by drug allocation and definition of postpartum haemorrhage in trial of oxytocin-ergometrine versus oxytocin

\begin{tabular}{|c|c|c|c|}
\hline $\begin{array}{l}\text { Definition of } \\
\text { postpartum } \\
\text { haemorrhage } \\
\text { (estimated blood } \\
\text { loss (ml)) }\end{array}$ & $\begin{array}{c}\text { No }(\%) \\
\text { allocated } \\
\text { to oxytoxin- } \\
\text { ergometrine } \\
(n=1730)\end{array}$ & $\begin{array}{c}\text { No }(\%) \\
\text { allocated } \\
\text { to oxytocin } \\
(n=1753)\end{array}$ & $\begin{array}{l}\text { Odds ratio } \\
(95 \% \\
\text { confidence } \\
\text { interval) }\end{array}$ \\
\hline$\geqslant 500 \mathrm{ml}$ & $286(165 \cdot 5)$ & $316(18 \cdot 1)$ & $0.90(0.75$ \\
\hline$>500 n$ & $259(14 \cdot 8)$ & $245(14 \cdot 2)$ & $0 \cdot 9$ \\
\hline None $(<500 \mathrm{ml})$ & $1444(83.5)$ & $1437(82 \cdot 0)$ & 1 \\
\hline Moderate $(500-999 \mathrm{ml})$ & $218(12 \cdot 6)$ & $233(13 \cdot 3)$ & $0.93(0.76$ \\
\hline Severe $(\geqslant 1000 \mathrm{ml})$ & $68(3.9)$ & $83(4 \cdot 7)$ & $0.82(0.59$ to 1.1 \\
\hline None $(\leqslant 500 \mathrm{ml})$ & $1485(85 \cdot 8)$ & $1494(85 \cdot 2)$ & 1 \\
\hline Moderate $(501-1000 \mathrm{ml})$ & $197(11 \cdot 4)$ & $190(10 \cdot 8)$ & $1.04(0.84$ \\
\hline Severe $(>1000 \mathrm{ml})$ & $48(2 \cdot 8)$ & $69(3.9)$ & $0.70(0.48$ to 1.01$)$ \\
\hline
\end{tabular}

TABLE V-Variables and outcomes in deliveries in trial of oxytocin-ergometrine versus oxytocin in third stage of labour. Figures are numbers (percentages) unless otherwise stated

\begin{tabular}{|c|c|c|c|}
\hline Detail & $\begin{array}{l}\text { Oxytocin- } \\
\text { ergometrine } \\
(n=1730)\end{array}$ & $\begin{array}{c}\text { Oxytocin } \\
(n=1753)\end{array}$ & $\begin{array}{c}\text { Odds ratio } \\
(95 \% \text { confidence } \\
\text { interval })\end{array}$ \\
\hline \multicolumn{4}{|l|}{ Maternal dichotomous variables (No (\%)): } \\
\hline Haemoglobin concentration $<9 \cdot 1 \mathrm{~g} / /^{\star}$ & $86(6 \cdot 4)$ & $94(7 \cdot 1)$ & $0.90(0.67$ to 1.22$)$ \\
\hline Therapeutic oxytocic & $301(17 \cdot 4)$ & $360(20 \cdot 6)$ & $0.80(0.69$ to 0.97$)$ \\
\hline Blood transfusion & $24(1 \cdot 4)$ & $16(0.9)$ & $1.52(0.81$ to 2.57$)$ \\
\hline Manual removal of placenta & $83(4 \cdot 8)$ & $94(4 \cdot 9)$ & $0.97(0.71$ to 1.31$)$ \\
\hline Third stage $>30 \mathrm{mins}$ & $44(2.5)$ & $47(2 \cdot 7)$ & $0.95(0.62$ to 1.44$)$ \\
\hline Third stage $>60 \mathrm{mins}$ & $30(1 \cdot 7)$ & $25(1 \cdot 4)$ & $1.22(0.71$ to 2.08$)$ \\
\hline Nausea & $467(28 \cdot 0)$ & $117(6 \cdot 7)$ & $5 \cdot 16(4 \cdot 22$ to $6 \cdot 31)$ \\
\hline Vomited & $358(21 \cdot 4)$ & $59(3 \cdot 3)$ & $7 \cdot 47(5.82$ to $9 \cdot 60)$ \\
\hline Diastolic blood pressure $>100 \mathrm{~mm} \mathrm{Hg}$ in labour ward & $15(0.9)$ & $3(0 \cdot 2)$ & $5 \cdot 10(1.67$ to $15 \cdot 55)$ \\
\hline Systolic blood pressure $>150 \mathrm{~mm} \mathrm{Hg}$ in labour ward & $107(6 \cdot 2)$ & $59(3.4)$ & $1.89(1.37$ to 2.60$)$ \\
\hline \multicolumn{4}{|l|}{ Maternal continuous yariable $e^{\star}$. } \\
\hline \multirow{2}{*}{\multicolumn{4}{|c|}{$\begin{array}{l}\text { Mean }(\mathrm{s}) \text { naemogiobin concentration }(\mathrm{g} / \mathrm{l}) \\
\text { Neonat dichotomous variablest: }\end{array}$}} \\
\hline & & & \\
\hline Apgar $<6$ at 5 mins & $15(0.9)$ & $19(1 \cdot 1$ & $0.79(0.40$ to 1.57$)$ \\
\hline Admission to neonatal intensive care unit & $317(18 \cdot 5)$ & $309(17 \cdot 9)$ & $1.04(0.88$ to 1.24$)$ \\
\hline Jaundice & $377(22 \cdot 0)$ & $394(22.8)$ & $0.85(0.49$ to 1.48$)$ \\
\hline Not fully breastfeeding on discharge & $252(14 \cdot 7)$ & $235(13 \cdot 6)$ & $1.10(0.90$ to 1.33$)$ \\
\hline \multicolumn{4}{|l|}{ Neonatal continuous variableł: } \\
\hline Mean (SD) birth weight (g) & $3323(604)$ & $3325(573)$ & $2 \cdot 2(-37$ to 41$) \|$ \\
\hline
\end{tabular}

*Oxytocin-ergometrine, $n=1339$; oxytocin, $n=1331$.

†Oxytocin-ergometrine, $\mathrm{n}=1713$; oxytocin, $\mathrm{n}=1727$.

fOxytocin-ergometrine, $n=1711$; oxytocin, $n=1727$.

|D Difference of mean $(95 \%$ confidence interval). study. With reference to the cut off point at $1000 \mathrm{ml}$, the alteration of definition (to severe $>1000 \mathrm{ml}$ ) led to the observed rate of severe postpartum haemorrhage with oxytocin-ergometrine $(2 \cdot 77 \%)$ being reduced somewhat more than the rate with oxytocin $(3.94 \%)$; in consequence, the ratio of odds came close to significance (odds ratio $0.70 ; 0.48$ to $1.01 ; p=0.06$ ). On the other hand, with reference to the cut off point at $500 \mathrm{ml}$, alteration of the definition (to moderate $>500 \mathrm{ml}$ ) led to the odds ratio for moderate or severe haemorrhage moving closer to the null value of 1.00 $(0.95 ; 0.78$ to $1.15 ; p=0.60)$. Table IV gives further details of the effect of redefinition. The remaining outcome variables are compared in table $\mathrm{V}$.

Postpartum haemoglobin concentration below $9 \cdot 1 \mathrm{~g} / 1$ occurred more often in women receiving oxytocin but not significantly so. Oxytocin-ergometrine was associated with a significantly lower rate of subsequent administration of therapeutic oxytocic agent (when analysed on basis of drug actually received there was no significant difference), a non-significantly higher rate of blood transfusion, and virtually no difference in rate of manual removal of the placenta. There was no difference in the proportion of long or very long third stage or in any neonatal outcomes. There were significantly higher rates of nausea, vomiting, and high blood pressure in women receiving oxytocin-ergometrine.

The risk estimates of women perceived as being at high risk of postpartum haemorrhage were not different from those perceived as being of low risk (data not shown).

\section{Discussion}

Although few would argue the merits of ergometrine in the treatment of postpartum haemorrhage, there is less agreement about which is the best prophylactic drug to use as part of the active management of the third stage of labour. If interventions are to be recommended it is crucial to ascertain their exact side effects and gauge their acceptability.

In the United Kingdom oxytocin-ergometrine is usually used. In Canada ${ }^{10}$ and parts of Europe oxytocin alone is the preferred drug, whereas ergometrine is used in Denmark and much of Africa. Even within individual countries the practice is not standardised. For example, of the three maternity units in Dublin the routine oxytocic agent at one is oxytocin; another uses ergometrine, and the other uses oxytocin-ergometrine.

At King Edward Memorial Hospital in Western Australia, before the Perth third stage trial began medical and midwifery staff varied in their preference of oxytocic agent. The rationale for the use of oxytocinergometrine, with its profound and clonic effect on uterine contraction, was that it was perceived as superior in terms of preventing postpartum haemorrhage. A suspected increased risk of hypertension and unpleasant side effects was accepted as the cost of the greater efficacy of oxytocin-ergometrine in preventing postpartum haemorrhage.

\section{BLOOD LOSS AND BIAS}

Blood loss was the primary end point assessed in this trial. Conscious of the subjective bias inherent in the clinical assessment of blood loss, we minimised the possibility of observer bias by blinding the attending midwives, the data collector, the women, and the study researchers as to which drug was given. This blinding did not make clinical assessment of blood loss any more reliable but did mean that any error in assessment was equally divided between the two study groups and that any difference in blood measurement could only be because of the different drugs used.

The exceptionally high rate of postpartum haemor- 
rhage reported in this study is worthy of comment. We chose $500 \mathrm{ml}$ as the threshold above which the diagnosis of postpartum haemorrhage should be recorded. This was the practice in the hospital before the study and is a widely used threshold. ${ }^{3}$ We believe that the high rate recorded is because of an increased awareness of blood loss associated with the implementation of this study.

This phenomenon is not new and has been described by Gilbert et al. ${ }^{11}$ Furthermore, the blood loss in our study was equally high in both arms of the trial. If the difference between our rate of postpartum haemorrhage and those observed elsewhere is accepted as artefactual, examination of the more severe postpartum haemorrhages may be more appropriate when comparing the results of this study with results of similar controlled trials; the cut off point of $1000 \mathrm{ml}$ produced a rate similar to that found in the Bristol third stage trial. ${ }^{6}$

Even at this level the rates between the two groups were not significantly different. Data from this study, however, confirmed that while low postpartum haemoglobin concentration is neither a sensitive nor specific marker for clinically assessed postpartum haemorrhage, it is significantly correlated with estimated intrapartum blood loss $\left(R^{2}=0.175 ; p<0.0001\right)$. Thus the significance of the very small difference in postpartum haemoglobin concentration that was not observed in antepartum concentration suggests that there may be a real though small increase in blood loss with oxytocin. There are no criteria by which to choose between the two measurements of postpartum haemorrhage examined in this study, but the results detailed in table IV suggest, firstly, that the incidence of moderate postpartum haemorrhage is unaffected by drug allocation and, secondly, that oxytocin-ergometrine has a small but real protective effect against severe postpartum haemorrhage. These data suggest that between $8 / 1000$ (postpartum haemorrhage $\geqslant 1000 \mathrm{ml}$ ) and $11 / 1000$ (postpartum haemorrhage $>1000 \mathrm{ml}$ ) women may have a postpartum haemorrhage attributable to the use of oxytocin rather than oxytocin-ergometrine in active third stage management.

The relative importance of this in the clinical context needs to be weighed against the significant disadvantages associated with oxytocin-ergometrine: a sevenfold increased risk of vomiting and a fivefold increased risk of increased diastolic blood pressure $(>100 \mathrm{~mm} \mathrm{Hg})$ in women who were normotensive before administration of the oxytocic. Whether or not this effect is likely to have an adverse clinical effect is uncertain, but it would seem to be a direct pharmacological effect rather than an indirect result of reduced blood loss.

\section{IMPLICATIONS}

One of the objectives of this study was to provide information which would assist the safe motherhood initiative programme in making recommendations for the most effective management in particular circum-

TABLE VI-Overview of randomised controlled trials (of oxytocin versus oxytocin-ergometrine) which used $5 \mathrm{IU}$ and $10 \mathrm{IU}$ oxytocin in relation to postpartum haemorrhage ( $\geqslant 500 \mathrm{ml}$ ). (Modified from the "Cochrane Database of Systematic Reviews": Review No 02999, 1993)

\begin{tabular}{|c|c|c|c|c|}
\hline Trial & Year & $\begin{array}{l}\text { Oxytocin- } \\
\text { ergometrine }\end{array}$ & Oxytocin & $\begin{array}{c}\text { Odds ratio } \\
\text { (95\% confidence } \\
\text { interval) }\end{array}$ \\
\hline \multicolumn{5}{|l|}{ Oxytocin 5 IU: } \\
\hline Nieminen and Jarvinen'12 & 1963 & $5 / 689$ & $9 / 689$ & $0.56(0.20$ to 1.61$)$ \\
\hline Dumoulin's & 1981 & $52 / 1000$ & $31 / 250$ & $0.31(0.18$ to 0.55$)$ \\
\hline Mitchell et al ${ }^{18}$ & 1992 & $6 / 230$ & $17 / 231$ & $0.37(0.16$ to 0.85$)$ \\
\hline Typical odds ratio & & & & $0.36(0.23$ to 0.55$)$ \\
\hline \multicolumn{5}{|l|}{ Oxytocin $10 \mathrm{IU}$ : } \\
\hline Dumoulin's & 1981 & $52 / 1000$ & $43 / 500$ & $0.56(0.36$ to 1.08$)$ \\
\hline Current research & 1992 & $286 / 1730$ & $316 / 1753$ & $0.90(0.75$ to 1.07$)$ \\
\hline Typical odds ratio & & & & $0.84(0.72$ to 0.99$)$ \\
\hline
\end{tabular}

\section{Clinical implications}

- Reducing the likelihood of postpartum haemorrhage by routine management of the third stage of labour could play an important part in reducing maternal morbidity and mortality

- This trial assessed the two most commonly used prophylactic oxytocic agents (oxytocin and Syntometrine (oxytocin-ergometrine)) to determine which had the lower risk of postpartum haemorrhage in routine use

- Rates of postpartum haemorrhage were similar with both drugs, but oxytocin-ergometrine was associated with nausea, vomiting, and hypertension

- The routine use of oxytocin-ergometrine has few advantages but several disadvantages

- Oxytocin 10 IU showed a greater protective effect than oxytocin 5 IU reported in a metaanalysis

stances in developing countries, so the issue of using a drug which may initiate uncontrolled vomiting or cause a rise in blood pressure in areas where eclampsia is already too common an occurrence is an important one. Women in general should be made aware of the increased risk of experiencing any of the described side effects and the increased potential risk of requiring antiemetic or antihypertensive treatment if oxytocinergometrine is to be administered. The use of oxytocin-ergometrine was not found to increase the risk of retained placenta or the need for general anaesthesia.

How do the results of our trial compare with those of similar studies? Five published trials attempted to determine the best prophylactic third stage oxytocic (Nieminen and Jarvinen, ${ }^{12}$ Vaughan-Williams et al, ${ }^{13}$ Docherty and Hooper, ${ }^{14}$ Dumoulin, ${ }^{15}$ and Symes. ${ }^{16}$ ) The major end points in the papers of VaughanWilliams et al and Symes were central venous pressure and serum prolactin, respectively. Both studies were very small. Docherty and Hooper reported only mean blood loss.

The Cochrane database of systematic reviews maintains an updated meta-analysis of all the randomised controlled trials in perinatal medicine and includes a recent overview of those studies which have compared oxytocin with oxytocin-ergometrine. In her commentary, Elbourne ${ }^{17}$ included the remaining two $0^{12} 15$ together with a trial by Mitchell $e t a l^{18}$ and the present Perth trial and concluded that there is a small but real reduction in the risk of postpartum haemorrhage associated with the use of oxytocin-ergometrine. Most of the studies included in this meta-analysis, however, chose to use $5 \mathrm{IU}$ rather than $10 \mathrm{IU}$ oxytocin. Examining the results of those trials which chose 5 IU shows a clear protective effect in terms of the risk of postpartum haemorrhage whereas analysis of the data retrieved from those trials which chose 10 IU oxytocin (to compare with oxytocin-ergometrine) shows a clearly reduced protective effect of the combined form (table VI).

\section{CONCLUSIONS}

In summary, our study taken alone revealed little advantage for the use of oxytocin-ergometrine over $10 \mathrm{IU}$ oxytocin when both are used as part of the routine active management of the third stage of labour. The protective effect of oxytocin-ergometrine over oxytocin $10 \mathrm{IU}$ in the more severe cases of postpartum haemorrhage is likely to be small and clinicians will 
have to weigh this against its clinically important disadvantages of a measurable increase in the common side effects of nausea, vomiting, and hypertension. The improved efficacy of $10 \mathrm{IU}$ of oxytocin over $5 \mathrm{IU}$ in reducing the risk of postpartum haemorrhage implies a dose-response relation that warrants further investigation. Perhaps $15 \mathrm{IU}$ or $20 \mathrm{IU}$ would provide even greater protection against the risk of postpartum haemorrhage. This question deserves attention by way of an appropriately sized randomised controlled trial.

We especially thank the women who participated in the study and the midwives, without whose enthusiasm and support the trial would not have succeeded. Our thanks to the data monitoring committee (Mrs Vivien Gee, Dr Anne Jacquier, and Dr Vivienne Dawes); Alkie Sussa (computing services, King Edward Memorial Hospital); medical coding; obstetricians; the pharmacy and haematology departments at King Edward Memorial Hospital and Osborne Park Hospital; the National Perinatal Epidemiology Unit, Oxford; Dr Paul Burton and Ms Maxine Croft from the Western Australian research institute for child health, Perth, for encouragement and advice; and Sandoz, Basle and Australia, for their interest and financial help. We also thank Mrs Helen Howells, who helped with the typing. This study was made possible by grants received from the World Health Organisation (safe motherhood initiative), the National Health and Medical Research Council, and the King Edward Memorial Hospital Research Foundation. Our special thanks to Dr Diana Elbourne (perinatal trials service at the National Perinatal Epidemiology Unit, Oxford) for her expertise, encouragement, and guidance.

1 Royston E, Armstrong S. Preventing maternal deaths. Geneva: World Health Organisation, 1989:30-42.
2 Kwast B. Post partum haemorrhage: its contribution to maternal mortality. Midwifery 1991;7:64-7.

3 Report of Technical Working Group. The prevention and management of post partum haemorrhage. Geneva: World Health Organisation, 1990. (WHO/MCH/90.7)

4 Prendiville $W$, Elbourne D, Chalmers I. The effect of routine oxytocic administration in the third stage of labour: an overview of the evidence from controlled trials. Brf Obstet Gymaecol 1988:95:3-16.

5 Garcia J, Garforth S, Ayers S. The policy and practice of midwifery study: introducion and meds.

6 Prendiville W, Harding JE, Elbourne DR, Stirrat GM. The Bristol third stage trial: "active" vs "physiological" management of the third stage of labour. BMF 1988;297:1295-300.

7 Begley CA. Comparison of "active" and "physiological" management of the third stage of labour. Midwifery 1990;6:3-17.

8 Prendiville W, Elbourne D. Care during the third stage of labour. In Chalmers I, Enkin M, Keirse M, eds. Effective care during pregnancy and childbirth. Oxford: Oxford University Press, 1988.

9 Elbourne D, Prendiville W, Chalmers I. Choice of oxytocic preparation for the routine use in the management of the third stage of labour: an overview of evidence from controlled trials. Br $\mathcal{F}$ Obstet Gynaecol 1988;295:17-30.

10 Baskett T. Management of the third stage of labour: a survey of practice among Canadian obstetricians. Fournal of Society of Obstetricians and Gynaecologists of Canada 1992 March/April:61-4.

11 Gilbert L, Porter W, Brown VA. Post partum haemorrhage-a continuing problem. Br f Obstet Gynaecol 1987;94:67-71.

12 Nieminen U, Jarvinen P. A comparative study of different medical treatments of the third stage of labour. Ann Chir Gynaecol 1963;53:424-9.

13 Vaughan-Williams C, Johnson A, Ledward R. Comparison of central venous pressure in the third stage of labour following oxytocic drugs and Diazepam. Fournal of Obstetrics and Gynaecology in the British Commonwealth 1974;81: 596-9.

14 Docherty P, Hooper $M$. Choice of an oxytocic agent for routine use at delivery. fournal of Obstetrics and Gynaecology 1981;2:60.

15 Dumoulin JG. A reappraisal of the use of ergometrine. Fournal of Obstetrics and Gynaecology 1981;1:178-81.

16 Symes JB. A study of the effect of erogmetrine on serum prolactin levels following delivery. Fournal of Obstetrics and Gynaecology 1984;5:36-8.

17 Elbourne DR. Prophylactic syntometrine vs oxytocin in third stage of labour. In: Enkin MW, Keirse MJNC, Renfrew MJ, Neilson JP, eds. Pregnancy and . Enkin MW, Keirse MJN, Renfrew MJ, Neilson JP, eds. Pregnancy and childbirth module. Oxford: Update Softwar

18 Mitchell G, Elbourne DE, Ashurst HA, Ibrahim G. The Salford third stage trial: oxytocin plus ergometrine versus oxytocin alone in the active management of the third stage of labour. Online fournal of Current Clinical Trials 1993 Aug 13:1993.

(Accepted 24 August 1993)
Academic Department of Public Health, St Mary's Hospital Medical School, University of London, London W2 1PG

David Miller, professor

Nicola Madge, senior research fellow

Judith Diamond, research statistician

Jane Wadsworth, senior

lecturer in medical statistics

Department of Community

Paediatrics, King's College

Hospital School of

Medicine and Dentistry,

University of London,

London

Euan Ross, professor

Correspondence to

Professor Miller.

$B M 71993 ; 307: 1171-6$

\title{
Pertussis immunisation and serious acute neurological illnesses in children
}

\author{
David Miller, Nicola Madge, Judith Diamond, Jane Wadsworth, Euan Ross
}

Abstract

Objective-To determine long term outcome in children who had a severe acute neurological illness in early childhood associated with pertussis immunisation.

Design-Follow up study of cases and matched controls.

Setting-Assessment of children at home and at school throughout Britain.

Subjects-Children recruited into the national childhood encephalopathy study in 1976-9 were followed up, with one of their two original matched controls, in 1986-9.

Main outcome measures-Performance in educational attainment tests; behaviour problems reported by teachers and parents; continuing convulsions; evidence of other neurological or physical dysfunction.

Results-Over $80 \%$ of cases and controls were traced. Case children were significantly more likely than controls to have died or to have some form of educational, behavioural, neurological, or physical dysfunction a decade after their illness. The prevalence of one or more of these adverse outcomes in case children who had been immunised with diphtheria, tetanus, and pertussis vaccine within seven days before onset of their original illness was similar to that in case children who had not been immunised recently. The relative risk for recent diphtheria, tetanus, and pertussis immunisation in children who had died or had any dysfunction in comparison with controls was 5.5 (95\% confidence interval 1.6 to 23.7). However, the number of cases associated with vaccine (12) was extremely small and statistically vulnerable, and other possible agents or predisposing factors could not be excluded.

Conclusions-Diphtheria, tetanus, and pertussis vaccine may on rare occasions be associated with the development of severe acute neurological illnesses that can have serious sequelae. Some cases may occur by chance or have other causes. The role of pertussis vaccine as a prime or concomitant factor in the aetiology of these illnesses cannot be determined in any individual case. The balance of possible risk against known benefits from pertussis immunisation supports continued use of the vaccine.

\section{Introduction}

The national childhood encephalopathy study was set up in Britain in 1976 after reports questioning the safety of pertussis vaccine ${ }^{12}$ had led to serious loss of confidence in the immunisation programme and a steep decrease in acceptance rates for this vaccine. ${ }^{34}$ The study aimed to examine the causes and outcome of severe acute neurological illnesses in young children with particular reference to the possible role of pertussis vaccine as an aetiological agent. ${ }^{5}$ The results showed a significant association between the onset of certain serious acute neurological illnesses and immunisation with diphtheria, tetanus, and pertussis vaccine in the previous seven days. ${ }^{5-7}$ Despite three years of active 